INTERnational JOURNAL OF MULtidisciplinaRy Research AND ANALysis

ISSN(print): 2643-9840, ISSN(online): 2643-9875

Volume 04 Issue 09 September 2021

DOI: 10.47191/ijmra/v4-i9-01, Impact Factor: 6.072

Page No.- $1200-1204$

\title{
Identifying Gender-Based Violence in Women from Aahh Laura Caller in the District of Los Olivos, Lima - 2021
}

\author{
Yals Molina Ozejo ${ }^{1}$, Angie Carolina Puican Coronado ${ }^{2}$, María del Pilar Rojas Zapata ${ }^{3}$, Flor Karina \\ Silva Saavedra ${ }^{4}$, Dafnne Nahomy Vega Solís ${ }^{5}$, Sánchez Uriarte Cristhian Jhair ${ }^{6}$ \\ 1,2,3,4,5,6 Universidad Cesar Vallejo \\ ORCID ID'S: ${ }^{10000-0001-7102-0701, ~}{ }^{2} 0000-0001-7618-0042,{ }^{3} 0000-0001-5785-7847,{ }^{4} 0000-0003-4605-1658$, \\ ${ }^{5} 0000-0003-3594-8793,{ }^{6} 0000-0002-61695489$
}

\begin{abstract}
The research entitled "Identifying gender violence in women of the AAHH Laura Caller in the district of Los Olivos, Lima - 2021". It aims to identify gender violence in women of the AAHH Laura Caller in the district of Los Olivos, Lima - 2021. The methodology had a quantitative approach, since the data collected will be measured through statistical analysis. Likewise, the research design is non-experimental, descriptive. The sample consisted of 50 women to whom a questionnaire was applied. The results showed the existence of physical violence, since it has been possible to identify slapping, pushing or throwing an object for having done something wrong as violence. As for psychological violence, it was possible to identify that the partners of most of the women had threatened to harm them and their children. In relation to sexual violence, it has been identified that the women's partners forced them to have sexual relations in exchange for money or goods. The conclusion is that there is a lack of knowledge of what physical, psychological and sexual violence is, and that they may be in danger of suffering mistreatment in their future relationships.
\end{abstract}

KEYWORDS: gender violence, physical, sexual violence.

\section{INTRODUCTION}

Gender violence is a very serious problem that has been increasing over the years, it is always present in our society with different degrees of intensity and violating human rights. Many women, for the simple fact of being women, are violated on a daily basis, in times when it is said to be peaceful.

In the past, women did not have the same rights as men, since it was erroneously believed that their only job was to take care of their children, take care of their husbands and take care of household activities, nor were their opinions taken into account because they were considered the weaker sex. As time goes by in history, women have been obtaining different rights such as employment, studying, voting in elections, etc. However, even in the 21st century, gender inequality is visible in our society and in some media certain behaviors are seen where sexism predominates (Alayo, 2018).

Female violence is present worldwide, regardless of social class, culture, religion, ethnicity, etc. Taking place in different spaces and maintaining a common root which is discrimination (Montes de Oca, 2014). Globally, according to WHO (2021) 1 in 3 women have suffered physical, sexual and psychological violence at some point in their lives, either by their partner or third parties.

In Peru, gender violence has been increasing considerably, in 2020, the Ombudsman's Office recognizes 132 cases of officially recognized femicides, 204 attempts and another 50 violent deaths of women that are under investigation. On the other hand, according to INEI data, recorded between January to December 2019, more than 5500 complaints of rape against women were collected, reporting that the rate of complaints of sexual abuse is an approximate 34 out of 100 thousand women, of the cases presented, $57.8 \%$ happen within the family.

That is why, given the data mentioned above, we observe that the rates of gender violence against women increase every year, therefore, we intend to know the existence of gender violence in the AAHH Laura Caller of Mz. A and B. of the District of Los Olivos, Lima - 2021, since in that place no statistical data were found that reveal the cases of violence that women must be suffering. The research problem is: How does gender violence manifest itself in women of the AA HH Laura Caller in the district of Los Olivos, Lima - 2021? 


\section{Identifying Gender-Based Violence in Women from Aahh Laura Caller in the District of Los Olivos, Lima - 2021}

As justification for this research, we consider from a social point of view that gender violence in our society continues to present itself as one of the most outstanding problems today, to date it is known that the most prominent cases are mostly directed towards women, so that according to UN records (2021), in the world there are approximately 736 million women, including young women, adolescents and girls who have suffered both physical and sexual harm. As for the theoretical justification, the study was supported by the theories of different authors, referring to our research variable with the purpose that this study will help future researchers to continue studying the problem of gender violence. From a practical point of view, the results obtained will be of great help to professionals who deal with this problem, such as the Ministry of Women's Affairs, the Women's Emergency Center, psychologists, etc.

The general objective is to identify gender violence in women of the AAHH Laura Caller in the district of Los Olivos, Lima - 2021. The following specific objectives were proposed: to identify physical violence in women of the AAHH Laura Caller in the district of Los Olivos, Lima - 2021; to identify psychological violence in women of the AAHH Laura Caller in the district of Los Olivos, Lima 2021; to identify sexual violence in women of the AAHH Laura Caller in the district of Los Olivos, Lima - 2021.

Jaramillo and Canaval (2020) in their thesis entitled "Gender violence: An evolutionary analysis of the concept", conclude that gender violence violates human rights, affects the dignity, physical and psychological integrity of women, their freedom and autonomy.

Gallegos, et al. (2020). In their research entitled "Self-esteem and psychological violence against university women in their relationships". They concluded that psychological violence does not have much relationship with the level of self-esteem in women.

Jacobi and Urbano (2020) in their research on, "Gender violence and self-esteem in women in a populated center of Huancavelica2020". They conclude that it is very necessary to carry out campaigns involving prevention and to know which are the most used measures for the prevention of gender violence and self-esteem of females.

Castillo, et al. (2017). In their research entitled. "Gender violence and self-esteem of women in the populated center Huanja Huaraz, 2017". They conclude that physical aggression experienced by women in the aforementioned population, is the one that is evidenced with a higher level of frequency, being above sexual, economic and psychological. Females who have been victims of aggression, through their self-esteem, feel failed and belittled before the social environment, so that, at a high level of aggression of economic, physical sexual and psychological type, a lower level of self-esteem is evidenced.

Benavides (2018) developed a research on "Gender violence in women in the neighborhood of Palermo - Lima 2017". She concludes that gender violence is a structural and social problem that puts women in conditions of inequality and subordination. The Ministry of Women and Vulnerable Populations (MIMP) (2016 defines) violence as any act or behavior, focused on the female group and is aggravated by discrimination originating from the coexistence of different identities such as age, race, ethnicity, class, etc., which cause the demise, evil or psychological, sexual and physical suffering of an individual, either within a private or public environment. This violence takes place in a context of exclusion towards women, within the family environment or outside it.

Rivadeneira (2017) tells us that physical violence, is that act that involves the use of force towards other people, this leaves fully visible traces on the body being easy to detect the victims. This facilitates the fact that the victim becomes aware of the situation that is being presented in order to proceed with the respective complaints, as a measure of self-protection.

Fernandez (2020) considers psychological violence to be any aggression carried out without physical contact. It is evidenced verbally, using denigrating adjectives, humiliating, devaluing and belittling the woman. All these acts cause much damage to the victim on an emotional level, this type of violence can begin subtly and grow little by little so that the victim will not realize it until she is already under the control of her victimizer in a dependent way, with fear, and taking attitudes out of her will.

Martínez (2018) mentions that sexual abuse is the most serious form of violation of rights, since it involves the total invasion of the body, leaves psychological sequelae and affects the woman's life project.

\section{METHODOLOGY}

\section{Type and design of research}

This research is quantitative in approach, as Hernández, et al. (2014) mentioned that the data collected will be measured through statistical analysis, in order to test the hypothesis in order to implement behavioral models and test theories. Likewise, this approach follows a sequence and is evidential. Each stage is very important so we cannot avoid steps.

This work is of Basic type, since according to Cegarra (2014) research is considered so because it seeks to increase the knowledge of what is being investigated and is used to better understand how certain conditions influence the behavior of the phenomenon under investigation, it was not created to solve such social phenomena, but is concerned only with knowing, explaining and predicting a theory with little or no intention of applying its results. In short, this research served to broaden our knowledge of the phenomenon studied. 


\section{Design}

It is a non-experimental - transversal, descriptive design, as Hernández, et al. (2014) mention that it is considered as such because it is not intended to manipulate the variable, only to observe the phenomena as they occur in their natural environment or reality and then analyze them. The researcher cannot influence the variables because they have already happened. At the same time, the data are collected at a single time or moment. Descriptive because it is intended to show the characteristics of a certain group.

\section{Population}

According to Hernández, et al (2014), they indicate that the population is the total set of people to be studied, in which the units have characteristics or similarities in common and give rise to the research data. In this case, the population consisted of 50 women over 18 years of age from the AA HH Laura Caller in the district of Los Olivos.

\section{Sample}

According to Hernández, et al (2014), the sample is made up of the population that will be part of the research, that is, the group or subset of people defined according to their characteristics related to the purpose of what we want to find out. In this study, the sample consisted of a total of 50 women from the AAHH Laura Caller of Mz. A and B. of the District of Los Olivos, all of whom are over 18 years of age.

\section{Sampling}

Hernández et al. (2014) indicated that, in non-probability convenience sampling, the choice of the population sample will not depend on probability, but on the characteristics of the study. It is not based on probability formulas, but the samples are conveniently available to the researchers. In this case, the researchers carried out the sample, selecting the women of the AA HH Laura Caller of Mz. A and B. of the District of Los Olivos considering the accessibility and voluntary participation of the mentioned women.

\section{Data collection techniques and instruments}

A survey was used as a technique for this research work, which was applied to women from the AA HH Laura Caller, in the district of Los Olivos, Lima. In order to identify gender violence against these women. According to Caro (2017). The survey is a technique in which you can obtain information about a subset of the population using a previously designed and structured questionnaire. The questionnaire, is composed in relation to the dimensions of the variable gender violence: "physical violence" made up of the questionnaire items from 1 to 3, "psychological violence" made up of items from 4 to 7 and, "sexual violence" made up of the questionnaire items made up of items from 8 to 10 . With the purpose of identifying physical, psychological and sexual violence in women of the AAHH Laura Caller of the district of Los Olivos. According to López and Fachelli (2015) the questionnaire is a form with a series of ordered and coherent questions, which is intended to obtain objective information from a subset of the population. This instrument is elaborated with a series of items.

\section{Procedures}

In order to obtain the information required for the research. Technological tools such as Google drive, Facebook, WhatsApp, etc. were used. It was not possible to conduct the survey in person because we are in a health emergency due to COVID. 19, and the only way to get in contact with the women of AA. HH Laura Caller was through the aforementioned means.

\section{Data analysis method}

For data analysis, the SPSS statistical program version 25 was used, since this software allows us to create tables and graphs that have been previously tabulated by assigning a certain value to each alternative, which in this case is the Likert scale.

\section{Ethical Aspects}

The following ethical aspects were determined: informed consent and confidentiality. In this regard, Gonzalo (2014) tells us that informed consent is a process by which the researcher explains in writing and verbally the agreements that the person participates voluntarily and with their consent in answering the questionnaire. Secondly, there is the ethical aspect of "confidentiality", where the identity of the people who participated in the study by providing their data will be protected. One of the ethical principles used is the principle of autonomy, which according to Martín (2014). It is defined as the ability to act freely and with conscience without being coerced by an external agent, it is based on Kant's philosophy which mentions that men should never be used as a means. On the other hand, there is the duty to assume the responsibilities of the actions done.

\section{RESULTS}

The results showed the existence of physical violence, since slapping, pushing or throwing an object for having done something wrong was not considered violence. With regard to psychological violence, it was found that the partners of most of the women 
had threatened to harm them and their children. In relation to sexual violence, it has been identified that the women's partners forced them to have sexual relations in exchange for money or goods.

\section{DISCUSSION}

According to the specific objective 1, which was to identify physical violence in women of the AAH Laura Caller in the district of Los Olivos, Lima - 2021, through the application of a survey to women over 18 years of age in this human settlement, it has been possible to identify that slapping, pushing or throwing an object for having done something wrong is not considered violence. In addition, there is a lack of knowledge of what physical violence is, and they may be in danger of suffering mistreatment in their future relationships. Thus, Castillo, et al. (2017) in their research entitled Gender violence and self-esteem of women in the town of Huanja - Huaraz, 2017, which aimed to determine the relationship between gender violence and the level of self-esteem of women in the population of Huanja - Huaraz, 2017. The level of analysis was quantitative, cross-sectional correlational. Thus concluding that the physical aggression experienced by the females of the aforementioned population, is the one that is evidenced with a higher level of frequency, being above sexual, economic and psychological aggression. Women who have been victims of aggression, through their self-esteem, feel that they are failures and undervalued in their social environment, so that a high level of economic, sexual, physical and psychological aggression shows a lower level of self-esteem. Therefore, Maria (2020) tells us that any action that is generated by physical force or any kind of weapon or object that can cause both internal and external injuries is considered as physical violence, which results in aggressiveness.

As for specific objective 2, which was to identify psychological violence in women of the AAHH Laura Caller in the district of Los Olivos, Lima - 2021, it has been possible to identify that the partner of most of the women in this human settlement has threatened to harm her and her children, as well as making unpleasant comments about their physical appearance. In addition, there is a lack of knowledge of what psychological violence is, since some of them do not consider the fact that they are insulted, called names or compared to someone else to be violence. Thus, Gallegos, et al. (2020). In their research work entitled Self-esteem and psychological violence against university women in their relationships, whose objective was to measure and correlate the level of self-esteem and psychological violence against women in their relationships, using a non-experimental design methodology with a quantitative approach. They concluded that there is no significant relationship between the two variables, but important information was obtained on self-esteem, which can be low not only as a consequence of psychological violence. Therefore, Asensi (2016) defines within the context of gender violence, that physical harm brings as a consequence to psychological violence, indicating that this type of violence is caused by a history of aggression at the physical level and at emotional levels. This suggests that psychological violence, according to their evaluations and belonging to a process of violence, occurs as an effect of all types of aggression.

In relation to specific objective 3, which was to identify sexual violence in women of the AAHH Laura Caller in the district of Los Olivos, Lima - 2021, it has been possible to identify that the women's partners forced them to have sexual relations in exchange for money or goods. Thus, Donoso, et al. (2019) in their research work entitled adolescence in the face of gender violence 2.0: Conceptions and experiences. They proposed as an objective to observe the different attitudes based on the experience of adolescents. As well as their reactions to different types of violence. The level of research is an analysis collected from the surveys used as an instrument of data collection. They came to conclude that it is necessary to make women aware of the risk they run in the different social networks, to make adolescents aware of the consequences of these, and to motivate young people who accuse violent acts that even involves the family and their study center in question. Therefore, Martínez (2018) mentions that sexual abuse is the most serious form of violation of rights, since it involves the total invasion of the body, leaves psychological sequels and affects the woman's life project.

\section{CONCLUSIONS}

It was possible to identify physical violence in the women of AA HH Laura Caller, from which it was determined that slapping, pushing or throwing an object for having done something wrong was not considered violence. In addition, there is a lack of knowledge of what physical violence is, and they may be in danger of suffering mistreatment in their future relationships.

Thus, psychological violence has been identified in the women of AA HH Laura Caller, from which threats and unpleasant comments about the physical appearance of the women by their partners were determined. Also, the lack of knowledge about the acts that are considered psychological violence.

It was also possible to identify sexual violence among the women of AA HH Laura Caller, where it was determined that some women are forced to have sexual relations in exchange for money or goods, and that there is also a lack of knowledge about any act that is considered sexual violence, such as groping and inappropriate touching. 


\section{REFERENCES}

1) Álvarez, L. (2020). The feminist movement in Mexico in the 21st century: Youth, radicalism and violence. Revista Mexicana De Ciencias Políticas y Sociales, 65(240), 147-175. Doi: http://dx.doi.org/10.22201/fcpys.244842xe.2020.240.76388

2) Ares, G. (2016). Antecedents of domestic violence in male perpetrators of gender violence [Master's thesis]. https://ruc.udc.es/dspace/bitstream/handle/2183/18000/AresMartinez_GracielaTFM_2016.pdf?sequence=2\&isAllowe $\mathrm{d}=\mathrm{y}$

3) Asensi, L. (2016). Psychological expert evidence in matters of gender violence. Revista Actualidad Penal, 26: 203. http://hdl.handle.net/10045/88728

4) Barrera, D. and Cárdenas G. (25 May2016). Women municipal presidents in Mexico: harassment and political violence (2010-2016). Revista de Ciencia Política. NO. 12,15-34.

http://revistas.pucp.edu.pe/index.php/politai/article/view/15211/15680.

5) Barredo, D. (2017). Gender violence in Ecuador: A study of university students. Estudios Feministas, 25(3),1313-1327. https://doi.org/10.1590/18069584.2017v25n3p1313

6) Castillo, E., Bernardo, J. and Medina, M. (2017). Gender violence and self-esteem of women in the Huanja - Huaraz population center, 2017. Horizonte Médico, 18(2), 47-52. https://doi.org/10.24265/horizmed.2018.v18n2.08

7) Cegarra, J. (2014). Methodology of scientific and technological research.

8) Ediciones: Diaz de Santos.

9) De León, C. (2018). Violence and gender in Latin America. Pensamiento iberoamericano,2,71-91. https://dialnet.unirioja.es/servlet/articulo?codigo $=2873321$

10) Donoso, Trinidad., Rubio, M. and Vilà, Ruth. (2018). Adolescence in the face of gender violence 2.0: conceptions, behaviors and experiences. Educación XX1, 21(1) 109-133. Available at:

https://www.redalyc.org/articulo.oa?id=70653466006

11) Gallegos, A., Sandoval, A., Espín M. and García, D. (2020) Self-esteem and psychological violence against university women in their intimate partner relationships. Teaching and Research in Psychology, 2(1),139-148.

12) Gonzalo, M. (2014). Informed consent in research. Revista Chilena de Anestesia, 43(4), 368-408. https://revistachilenadeanestesia.cl/consentimiento-informado-en- investigación/

13) Hernández, R., Fernández, C. \& Baptista, M. (2014). Research methodology. Mexico: McGRAW-HILL.

14) Jaramillo, C. \& Canaval, G. (2020). Gender violence: An evolutionary analysis of the concept. Univ. Health.22(2):178- 185. https://doi.org/10.22267/rus.202202.189

15) Martínez, M. (2018). Violence and sexual abuse in childhood and adolescence. Revista de la sociedad uruguaya de ginecología de la infancia y adolescencia, 7(3), 7- 93.

16) Martínez, A. (2016). Violence conceptualization and elements for its study. Política y Cultura, 46, 7-31.

17) http://www.redalyc.org/articulo.oa?id=26748302002

18) Martin, S. (2014). Application of ethical principles to research methodology. Nursing in Cardiology, 20 (58-59). 27-30. https://www.enfermeriaencardiologia.com/revista/revistas/58-58/ 